\title{
Enhancement of the 1988 northern U.S. drought due to wildfires
}

\author{
Yongqiang Liu \\ Forestry Sciences Laboratory, Forest Service, U.S. Department of Agriculture, Athens, Georgia, USA
}

Received 11 January 2005; revised 4 March 2005; accepted 21 April 2005; published 20 May 2005.

[1] Drought provides a favourable environment for the ignition and spread of intense wildfires. This study examines the opposite relationship between the two natural disasters, that is, the role of wildfires in the development of drought. The case of the 1988 northern U.S. wildfires is investigated. Emissions of smoke particles from the wildfires and the resulting optical depth are estimated using wildfire data and empirical algorithms. Radiative forcing of the smoke particles and atmospheric response are simulated using a regional climate model. It is found that absorption of solar radiation by smoke particles weakens the North America trough in the middle latitudes, which is a major generator of precipitation in the Midwest. Rainfall in this region is therefore reduced, providing evidence for the role of wildfires in enhancing drought. Citation: Liu, Y. (2005), Enhancement of the 1988 northern U.S. drought due to wildfires, Geophys. Res. Lett., 32, L10806, doi:10.1029/2005GL022411.

\section{Introduction}

[2] Intense wildfire and drought are two natural disasters that often happen together during a wildfire season, as indicated by the statistically significant correlation between them [Liu, 2004]. It has been long recognized that wildfires are much easier to ignite and spread under drought conditions [Pyne et al., 1996]. The specific role of wildfires in drought development, however, is still unclear.

[3] Absorbing aerosols can have important effects on climate. Recent measurement and modeling studies indicate that atmospheric absorbing aerosols can reduce clouds [e.g., Hansen et al., 1997; Kaufman et al., 2002]. It was observed during the Indian Ocean Experiment that cloud cover was very sparse where high concentration of soot aerosols was present [Ackerman et al., 2000]. By absorbing solar radiation, the aerosols can increase air temperature and reduce relative humidity. Clouds therefore can be reduced. Absorbing aerosols were found to be a contributor to the long-term precipitation anomalies in China [Menon et al., 2002]. The satellite measured clouds during a biomass burning season in the Amazon region were reduced by heavy smoke [Koren et al., 2004], which was confirmed by modeling [Liu, 2005]. Finally, the pioneering studies on nuclear winter [e.g., Cotton, 1985; Malone et al., 1986; Golding et al., 1986; Giorgi and Visconti, 1989] have provided important indication on the regional climate effects of atmospheric injections of massive amounts of smoke particles.

[4] The cloud reduction due to absorbing aerosols suggests that wildfires, which release a large amount of absorbing smoke aerosols [e.g., Crutzen and Andreae,

This paper is not subject to U.S. copyright.

Published in 2005 by the American Geophysical Union.
1990], could enhance drought. The present study seeks to provide modeling evidence for the possible role of wildfires by examining the atmospheric response to the 1988 northern Rocky Mountain wildfires.

\section{The $\mathbf{1 9 8 8}$ Northern U.S. Drought and Wildfires}

[5] The northern United States experienced a severe drought in 1988, which started in late April with extreme precipitation deficiencies in June. This period was among the driest of the 20th century in the continental United States [Karl et al., 1988; Ropelewski, 1988]. By July 1988 precipitation returned to normal or above normal in the Northeast, but was still well below normal in the northern Midwest and eastern West, where monthly rainfall was less than $75 \mathrm{~mm}$ (Figure 1). Meanwhile, rainfall was above normal in the Southwest and western Southeast, and below normal in the eastern Southeast.

[6] Numerous wildfires broke out in the northern Rocky Mountains, including the catastrophic Yellowstone National Park fires [Romme and Despain, 1989], mostly during July. Hundreds of thousands of acres of forest were burned by the Yellowstone fires alone. In comparison with some other wildfires such as those of southern California during the Fall of 2003, the 1988 northern Rocky Mountain wildfires more likely played an important role in affecting the atmosphere because they occurred in the summer months. Solar radiation is the greatest during this time of year and cloud cover is relatively small if an existing drought is developing. Therefore, perturbation in incoming solar radiation due to absorption and reflection of smoke particles should be large. Furthermore, these fires occurred in the mid-latitudes, where the planetary westerly often is dynamically unstable. As a result, large atmospheric response to fire disturbance is expected.

\section{Methodology}

\subsection{Emission}

[7] Emissions of smoke particles of $10 \mu \mathrm{m}$ or smaller in diameter were estimated using the empirical formula $E=A$ $S L$, where $E$ is emission (in mass); $A$ land area burned; $L$ effective fuel consumption or fuel loading factor (mass of forest fuel per unit land area burned) and $S$ emission factor (mass of pollutant per unit mass of forest fuel consumed). The burning area data were obtained from a wildland fire information system. A detailed description of the formula, data, and parameter specification was given by Liu [2004].

\subsection{Optical Depth}

[8] The total optical depth (TOD) of smoke particles was estimated using the formulas $\tau_{d}=\sigma t_{s} E$ and $\tau=f_{R H} \tau_{d}$ [Charlson et al., 1992], where $\tau$ and $\tau_{d}$ are area mean optical depth of smoke and its value at dry condition 


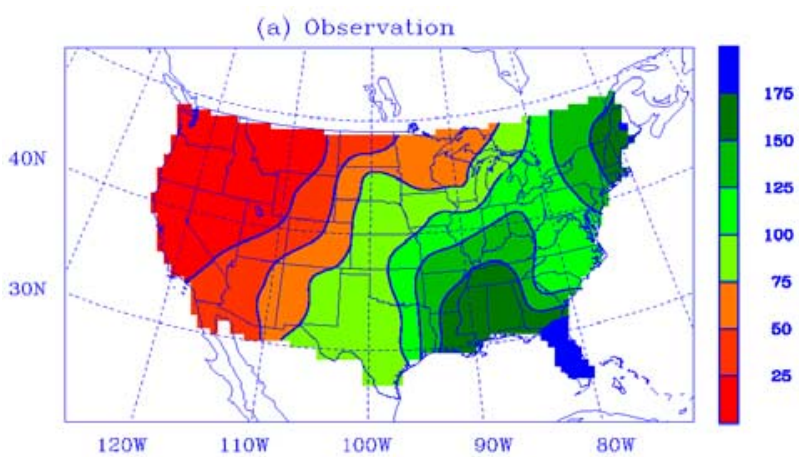

(b) Anomaly

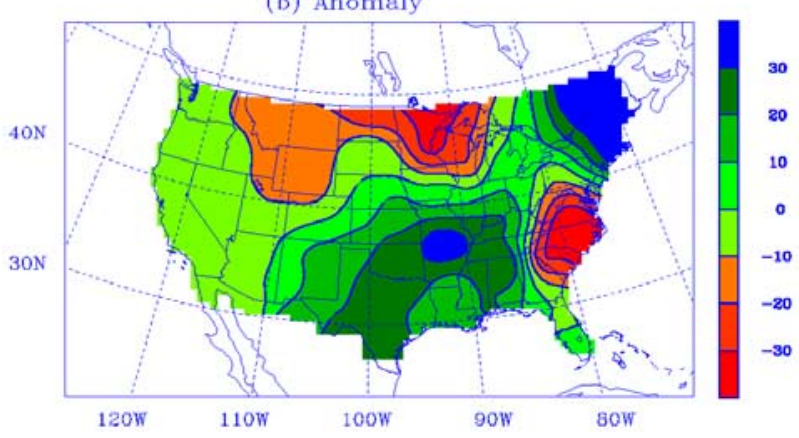

Figure 1. The observed precipitation (in mm). (a) Monthly rainfall of July 1988. (b) The difference in July rainfall between 1988 and the average over 1895-2002.

(relative humidity $R H=30 \%$ ); $\sigma$ and $t_{s}$ the molar scattering cross section of smoke particles and life time of smoke particles (assuming $5 \mathrm{~m}^{2} \mathrm{~g}^{-1}$ and 6 days, respectively [Penner et al., 1992]); $E$ smoke emission; and $f_{R H}$ a hydroscopic factor. A single scattering albedo (SSA) at midvisible wavelength of 0.88 was specified based on the Amazonian measurement [Eck et al., 1998]. The spectral dependences of TOD and SSA were specified based on the measurements of biomass burning [Ross et al., 1998].

\subsection{Atmospheric Response}

[9] The National Center for Atmospheric Research (NCAR) regional climate model (RegCM) [Giorgi and Bates, 1989; Dickinson et al., 1989; Giorgi et al., 1999] was used to simulate absorption and reflection (i.e., direct radiative forcing (DRF)) of smoke aerosols from the 1988 July fires and the resulting atmospheric perturbations. The simulation domain is centered at $40^{\circ} \mathrm{N}, 99^{\circ} \mathrm{W}$ and covers the continental U.S. and the adjacent oceans, and parts of Canada and Mexico (see Figure 1). There are 97 by 61 grid points with a resolution of $60 \mathrm{~km}$. The vertical direction has 14 layers. The initial and lateral boundary meteorological conditions were interpolated from the analysis of the European Center for Medium Range Weather Forecast. Soil water content is initialized depending on type of vegetation [Giorgi and Bates, 1989]. Smoke particles were assumed to be distributed in a layer between the ground and about $2.5 \mathrm{~km}$ evenly in space within each state and in time over the simulation period. Actual horizontal pattern and vertical profile could be much more complex. The transport of smoke particles is not included in the model and the role of smoke particles as cloud condensation nuclei is not examined in this study. Smoke absorption only occurs over the fire areas (The areas will be shown in the next section).

[10] A smoke simulation with the smoke optical properties described above and a control simulation without smoke particles were conducted. DRF of smoke is approximately measured by the difference in the net solar radiation flux at the top model level between the smoke and control simulations. Perturbation in precipitation as well as any other atmospheric field is measured by the difference in the field between the two simulations.

\section{Results}

[11] The emissions of smoke particles during July 1988 are up to $300 \mathrm{~kg} \mathrm{~km}^{-2}$ over Wyoming, Montana and Idaho in the northeastern West (Figure 2). In comparison, they are about one third of the amount during June or August 1988. The dry optical depth of up to 0.3 is produced by the smoke particles over the fire region. This leads to the radiative forcing of up to $-9 \mathrm{Wm}^{-2}$. Note that, because clouds change with time during the RegCM simulation, this radiative forcing is actually a combination of the perturbations in solar radiation caused by smoke particles through scattering and absorption and by the resulting cloud perturbation.

[12] Figure 3 shows the simulated precipitation and the perturbation due to smoke particles from the July 1988 wildfires. The simulated geographic pattern of precipitation (i.e., a general increase in rainfall from the west to east coast) is in agreement with the observation. Rainfall in the Midwest, however, is overpredicted. In addition, the major rainfall regime in the Southeast is shifted northeastward from the observed location. The precipitation perturbation in response to radiative forcing of smoke aerosols is mostly negative in the Northwest, with the largest reduction of about $-30 \mathrm{~mm}$ found in the northeastern Midwest. Accompanied are positive perturbation in the Southwest, southeastern Midwest, and Northeast, and negative perturbation in the Southeast. A t-test to daily rainfall in the Great Lakes area $\left(90-80^{\circ} \mathrm{W}, 45-49^{\circ} \mathrm{N}\right)$ indicates that the smokeinduced reduction is significant at the confidence level of $95 \%$ for rainfall at many grid points, and $80 \%$ for the areaaveraged rainfall.

[13] A number of experiments are carried out to evaluate uncertainty in the simulated rainfall perturbation due to the uncertainty in determining smoke property. The averaged

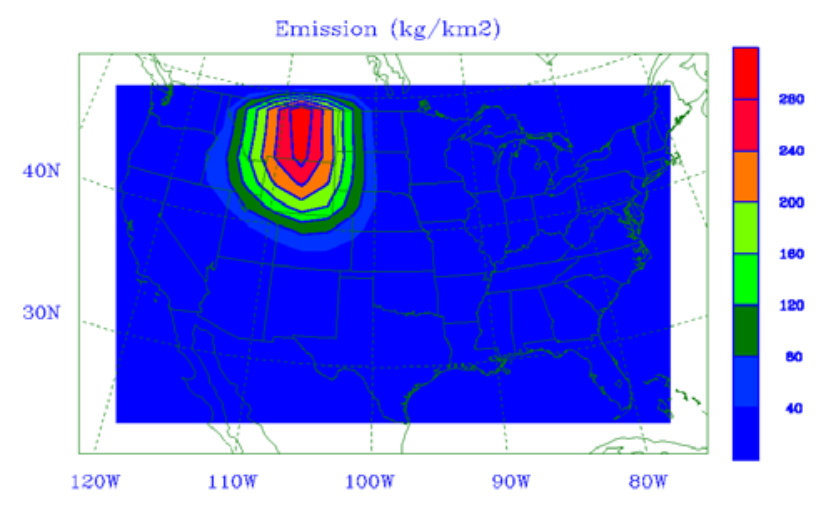

Figure 2. Emissions of smoke particles from wildfires during July 1988 (in $\mathrm{kg} \mathrm{km}^{-2}$ ). 
(a) Simulation

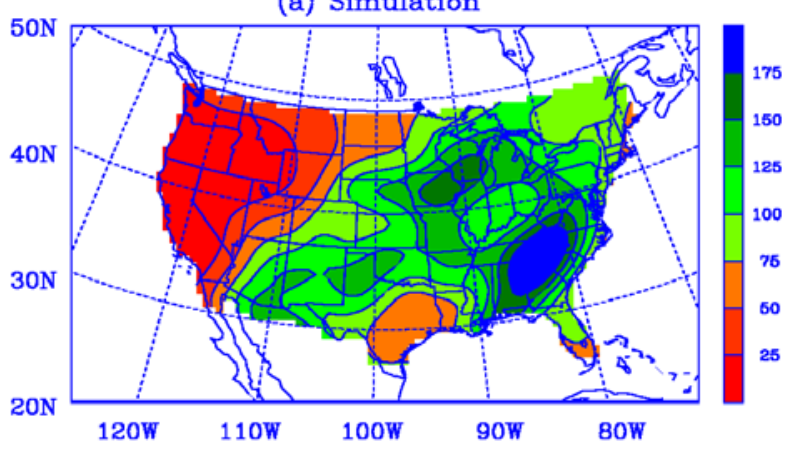

(b) Perturbation

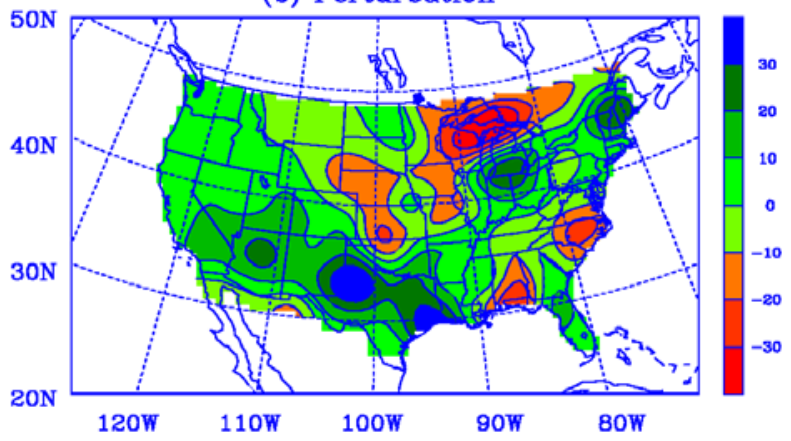

Figure 3. The simulated precipitation of July 1988 with RegCM (in $\mathrm{mm}$ ). (a) The simulation without smoke particles. (b) The difference between the simulations with and without smoke particles.

rainfall perturbation over the Great Lakes in Figure $3 \mathrm{~b}$ is $-16.8 \mathrm{~mm}$. This value is changed to -18.2 and $-14.1 \mathrm{~mm}$ when the smoke amount increases and decreases by $50 \%$, respectively, to -24.0 and $-8.4 \mathrm{~mm}$ when the height of the smoke layer increases and decreases by about $1 \mathrm{~km}$, respectively, and to $-24.8 \mathrm{~mm}$ when $50 \%$ of the smoke particles are removed from the fire areas to the downwind. Experiments are also carried out to evaluate the possible effects of the model internal variability [Giorgi and Bi, 2000] by randomly imposing small perturbations on initial temperature or a wind component. Similar to Figure $3 b$, an overall rainfall reduction in the Great Lakes area is obtained from these experiments though its magnitude and location might be different.

[14] Due to the prior drought, actual initial soil moisture in the northern United States for July 1988 was likely smaller than that specified in the simulations. When initial soil moisture is reduced by $5 \%$ in this region, the simulated rainfall in the Great Lakes area is about $25 \mathrm{~mm}$ less than the value in Figure 3a. The smoke-induced rainfall reduction is more significant in the northern Midwest. In addition, the area of rainfall reduction extends to the Northeast.

[15] Perturbations in the atmospheric circulations provide a possible explanation to the geographic pattern of precipitation perturbation. The simulated atmospheric geopotential height (Figure 4a) displays a planetary-scale system in the middle latitudes with a ridge and a trough over the western and eastern North America, respectively. This system corresponds to the westerly airflows. South of the westerly airflows are high pressure systems over the Southwest, the Pacific Ocean, and the Atlantic Ocean. In addition, there is a tropical easterly trough over the Mexican coast.
Corresponding to the ridge and trough with the westerly system are a warm and a cold tongue (Figure $4 \mathrm{~b}$ ).

[16] Over the fire area of the northeastern West, it is expected that absorption of solar radiation by smoke particles releases heat in the upper smoke layer. This causes different changes along and across the westerly airflows. The prevailing airflows transport the warmer air to the downwind, which is converged in the trough area over the Midwest. The trough is therefore weakened, as shown in Figure $4 \mathrm{c}$. Clouds and rainfall are therefore reduced. The reduced clouds lead to more incoming solar radiation, which partially contributes to the slightly positive temperature perturbation (Figure 4d). In the meridional direction, on the other hand, the released heat reduces the temperature gradient south to the fire area, which weakens the westerly airflows. This reduces the anti-cyclonic shear of airflows and therefore weakens the high over the southwestern West (Figure 4c). Clouds and rainfall are therefore increased, leading to the negative temperature perturbation (Figure 4d).

[17] For the case examined in this study, simulated rainfall in the Northwest is reduced due to wildfires, indicating that wildfires could enhance an existing drought in a region. The intensity and extent of the rainfall reduction, however, depend on model specification of smoke loading and initial atmospheric and soil conditions, as indicated by a number of sensitivity experiments. In addition, it is interesting to note the similarity to a certain extent in the spatial pattern between the rainfall perturbation due to wildfires (Figure 3b) and the observed precipitation anomaly (Figure 1b). Both are negative in the West, Midwest, and the eastern Southeast, and positive in the Southwest and Northeast, suggesting that the atmospheric response to the northern Rocky Mountain wildfires might have been one of the contributing factors for the nationwide precipitation anomalies during July 1988.
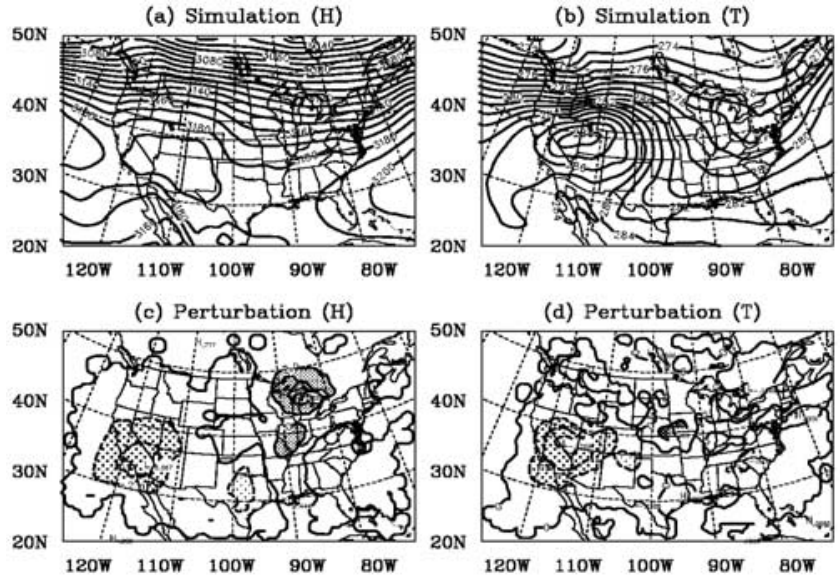

Figure 4. The July 1988 atmospheric fields on $700 \mathrm{hPa}$ simulated with RegCM. (a-b) Simulated geopotential height (in $\mathrm{m}$ ) and temperature (in $\mathrm{K}$ ). The intervals are $10 \mathrm{~m}$ and $1 \mathrm{~K}$. (c-d) The corresponding difference between the simulations with and without smoke particles. The intervals are $2 \mathrm{~m}$ and $0.25 \mathrm{k}$. The solid and dashed lines represent positive and negative values. The values (c) greater than $2 \mathrm{~m}$ or smaller than $-2 \mathrm{~m}$ and (d) greater than $0.25 \mathrm{~K}$ or smaller than $-0.25 \mathrm{~K}$ are shaded. 
[18] The mechanisms for drought origin and development have been an extremely important climate issue over the past decades. Many studies have led to the conclusion that anomalies with the internal components of the climate system such as sea surface temperature [Trenberth et al., 1988] and soil moisture [Giorgi et al., 1996] are the major responsible factors for the persistent atmospheric anomalies. Wildfires can be an external factor of the climate system for drought development.

[19] Acknowledgments. The author wishes to thank two anonymous reviewers for their valuable comments and suggestions. This study was supported by the USDA Forest Service National Fire Plan through the Southern High-Resolution Modeling Consortium (SHRMC). The editorial support from James Forbus is appreciated.

\section{References}

Ackerman, A. S., O. B. Toon, D. E. Stevens, A. J. Heymsfield, V. Ramanathan, and E. J. Welton (2000), Reduction of tropical cloudiness by soot, Science, 288, 1042-1047.

Charlson, R. J., S. E. Schwartz, J. M. Hales, R. D. Cess, J. A. Coakley Jr., J. E. Hansen, and D. J. Hoffman (1992), Climate forcing by anthropogenic sulfate aerosols, Science, 255, 423-430.

Cotton, W. R. (1985), Atmospheric convection and nuclear winter, Am. Sci., $73,275-280$.

Crutzen, P. J., and M. O. Andreae (1990), Biomass burning in the tropics: Impact on atmospheric chemistry and biogeochemical cycles, Science, 250, 1669-1678.

Dickinson, R. E., R. M. Errico, F. Giorgi, and G. T. Bates (1989), A regional climate model for the western U.S., J. Clim., 15, 383-422.

Eck, T. F., B. N. Holben, I. Slutsker, and A. Setzer (1998), Measurements of irradiance attenuation and estimation of aerosol single scattering albedo for biomass burning aerosols in Amazonia, J. Geophys. Res., 103, $31,865-31,878$

Giorgi, F., and G. T. Bates (1989), The climatological skill of a regional model over complex terrain, Mon. Weather Rev., 117, 2325-2347.

Giorgi, F., and X. Bi (2000), A study of internal variability of a regional climate model, J. Geophys. Res., 105, 29,503-29,521.

Giorgi, F., and G. Visconti (1989), Two-dimensional simulations of possible mesoscale effects of nuclear war fires: 2. Model results, J. Geophys. Res., 94, $1145-1163$

Giorgi, F., L. O. Means, C. Shields, and L. Mayer (1996), A regional model study of the importance of local versus remote controls of the 1988 drought and the 1993 flood over the central United States, J. Clim., 9, $1150-1162$.
Giorgi, F., Y. Huang, K. Nishizawa, and C. Fu (1999), Seasonal cycle simulation over eastern Asia and its sensitivity to radiative transfer and surface processes, J. Geophys. Res., 104, 6403-6424.

Golding, B. W., P. Goldsmith, N. A. Machin, and A. Slingo (1986), Importance of local mesoscale factors in any assessments of nuclear winter, Nature, 319, 301-303.

Hansen, J., M. Sato, and R. Ruedy (1997), Radiative forcing and climate response, J. Geophys. Res., 102, 6831-6864.

Karl, T. R., et al. (1988), The 1988 drought in the United States: Just another drought?, Eos Trans. AGU, 69, 1069.

Kaufman, Y. J., D. Tanre, and O. Boucher (2002), A satellite view of aerosols in the climate system, Nature, 419, 215-223.

Koren, I., Y. J. Kaufman, L. A. Remer, and J. V. Martins (2004), Measurement of the effects of Amazon smoke on inhibition of cloud formation, Science, 303, 1342-1345.

Liu, Y.-Q. (2004), Variability of wildland fire emissions across the continuous United States, Atmos. Environ., 38, 3489-3499.

Liu, Y.-Q. (2005), Atmospheric response and feedback to smoke radiative forcing from wildland fires in tropical South America, Agric. For. Meteorol., in press.

Malone, R. C., L. H. Auer, G. A. Glatzmayer, M. C. Wood, and O. B. Toon (1986), Nuclear winter: Three-dimensional simulations including interactive transport, scavenging, and solar heating of smoke, J. Geophys. Res., 91, 1039-1053.

Menon, S., J. E. Hansen, L. Nazarenko, and Y. Luo (2002), Climate effects of black carbon aerosols in China and India, Science, 297, 2250-2253.

Penner, J. E., R. E. Dickinson, and C. S. O’Neill (1992), Effects of aerosol from biomass burning on the global radiation budget, Science, 256, $1432-1434$

Pyne, S., P. L. Andrews, and R. D. Laven (1996), Introduction to Wildland Fire, 769 pp., John Wiley, Hoboken, N. J.

Romme, W. H., and D. G. Despain (1989), The Yellowstone fires, Sci. Am., 261, 36-44.

Ropelewski, C. F. (1988), The global climate for June-August 1988: A swing to the positive phase of the Southern Oscillation, drought in the United States, and abundant rain in monsoon areas, J. Clim., 1, 11531174.

Ross, J. L., P. V. Hobbs, and B. N. Holben (1998), Radiative characteristics of regional hazes dominated by smoke from biomass burning in Brazil: Closure tests and direct radiative forcing, J. Geophys. Res., 103, 31,92531,941 .

Trenberth, K. E., G. W. Branstator, and P. A. Arkin (1988), Origins of the 1988 North American drought, Science, 242, 1640-1645.

Y. Liu, Forestry Sciences Laboratory, Forest Service, USDA, 320 Green St., Athens, GA 30602, USA. (yliu@fs.fed.us) 